\title{
Caudal epidural blood patch for the treatment of a paediatric subarachnoid- cutaneous fistula
}

This clinical report describes the performance of an epidural blood patch in a four-year-old child with acute lymphocytic leukaemia, who developed a subarachnoid-cutaneous fistula from repeated lumbar punctures for chemotherapy. The epidural blood patch was performed using an \#18-gauge epidural catheter threaded through a \#16-gauge intravenous catheter via the caudal approach. This approach was successful in a child whose lumbar epidural anatomy was distorted due to a collection of subcutaneous cerebrospinal fluid making identification of the epidural space by the usual lumbar approach very difficull. This report demonstrates an alternative technique for the performance of an epidural blood patch.

Cette observation commente le succès d'une injection épidurale de sang autologue ("blood patch") chez un jeune leucémique de quatre ans porteur d'une fistule sous-arachnoïdo-cutanée à la suite de ponctions lombaires répétées pour chimiothérapie. Linjection a été réalisée grâce à un cathéter épidural $18 \mathrm{G}$ passé à travers un cathéter intraveineux $16 G$ par l'approche caudale. Cette approche a été rendue nécessaire par le bouleversement anatomique causé par une collection de liquide céphalorachidien qui rendait lidentification de l'espace épidural par l'approche lombaire habituelle très difficile. Cette observation montre qu'il est possible d'utiliser une technique alternative pour effectuer une injection épidurale de sang autologue.

\section{Key words}

ANAESTHESIA: paediatric;

ANAESTHETIC TECHNIQUES: epidural, caudal;

COMPLICATIONS: subarachnoid-cutaneous fistula, postdural puncture headache, blood patch.

From the Department of Anaesthesia, Royal University

Hospital, Saskatoon, Saskatchewan.

Address correspondence to: Dr. V.K. Comfort, Department of Anaesthesia, Royal University Hospital, 103 Hospital Drive, Saskatoon, Saskatchewan S7N 0W8.

Accepted for publication 25 February, 1995.
There are few reports describing the epidural blood patch as a treatment for postdural puncture headache and subarachnoid-cutaneous fistula in children. ${ }^{1,2}$ This clinical report describes an alternative blood patch technique with an epidural catheter introduced into the epidural space using the caudal approach in a paediatric patient.

\section{Case report}

A four-year-old boy with acute lymphocytic leukaemia (ALL) presented with a persistent subarachnoidcutaneous fistula and a large collection of subcutaneous cerebrospinal fluid (CSF) following lumbar puncture for chemotherapy.

He had undergone weekly lumbar punctures for intrathecal injection of methotrexate. These were performed by the paediatric oncologist with a \#22-gauge Quincke spinal needle at the $\mathrm{L}_{3-4}$ interspace. Unfortunately, during the last intrathecal injection the child moved when the spinal needle was positioned in the intrathecal space and, subsequently, a subarachnoid-cutaneous fistula developed.

The patient did not seem to be distressed from the continuous leak of CSF. The parents had noticed increasing oedema over the lower back and continuous saturation of the dressings over the puncture site. Physical examination of the child revealed a somewhat lethargic, balding and pale four-year-old with normal vital signs. The neurological examination was normal with no demonstrable meningeal signs. The subcutaneous tissue over the thoraco-lumbo-sacral spine was markedly oedematous. A continuous leak of clear fluid, presumed to be CSF, from the previous lumbar puncture site was apparent. The remainder of the examination was unremarkable. Laboratory examinations revealed mild anaemia, neutropaenia, normal platelet count and slightly increased PTT (Hgb $108 \mathrm{~g} \cdot \mathrm{L}^{-1}$; WBC 4.5; platelets 138,000; INR 0.8; PTT control $30 \mathrm{sec}$, patient $35 \mathrm{sec}$ ). Various options are available for the treatment of subarachnoid-cutaneous fistula, ${ }^{3-13}$ including conservative management, surgical repair and epidural blood 
patch. A trial of conservative management (bed rest and fluids) was attempted with no improvement in this patient's symptoms in $72 \mathrm{hr}$. Surgical repair was considered to be the last resort in this immunocompromised and anaemic patient. After discusssion amongst the parents, the paediatric oncologist, the neurosurgeons and the anaesthetists, the decision was made to perform an epidural blood patch before attempting surgical repair.

The child was brought to the operating room on a day-surgery basis after appropriate fasting. General anaesthesia was induced after atropine $\left(0.01 \mathrm{mg} \cdot \mathrm{kg}^{-1}\right)$ with propofol $\left(2.5 \mathrm{mg} \cdot \mathrm{kg}^{-1}\right)$ and maintained with spontaneous ventilation of halothane, $\mathrm{N}_{2} \mathrm{O}$, and $\mathrm{O}_{2}$. The airway was secured using a laryngeal mask. With the child in the left lateral decubitus position and under sterile conditions a \#20-gauge Hustead needle (Concord/Portex, Keene, New Hampshire, U.S.A. 03431) was introduced at the $\mathrm{L}_{3-4}$ interspace. The epidural space was located using the loss of resistance technique with air. Upon identification of what was thought to be the epidural space, a gush of CSF ensued after the syringe was removed from the hub of the needle. The procedure was repeated by another anaesthetist with the same results. Two possibilities were considered: (1) the epidural space was filled with CSF under pressure, or (2) both anaesthetists punctured the dura.

A caudal approach was then attempted using a \#17 Hustead needle. The epidural space was identified under sterile conditions using loss of resistance technique with air. The epidural catheter however could not be advanced. Therefore, the caudal approach to the epidural space was repeated using a \#16-gauge intravenous needle and catheter. Loss of resistance was felt and the teflon catheter was advanced over the intravenous needle. The distance from the previous intrathecal methotrexate injection site to the hub of the intravenous catheter was measured on the skin. An \#18-gauge adult epidural catheter was then easily advanced the predetermined distance through the \#16-gauge intravenous catheter. The patient's blood was drawn from a peripheral vein using aseptic technique, and injected into the epidural space through the epidural catheter. The blood was injected using a twenty $\mathrm{ml}$ syringe. The initial resistance to injection was similar to that perceived when one injects local anaesthetics through an epidural catheter. When $8 \mathrm{ml}$ of blood had been injected the resistance increased acutely and the injection was discontinued. Immediately after injection, the steady trickle of CSF through the skin stopped. The patient was awakened and transferred to the postanaesthesia care unit in stable condition. Neurological examination, at this time, demonstrated no deficits in the lumbosacral distribution. The patient was discharged home the same day.

The parents of the child were advised to watch for symptoms of back pain, bowel and bladder dysfunction or fever. The child was brought to the emergency room two days later because he developed a fever. The dressing on his back was dry with no evidence of further leakage. The previously present subcutaneous oedema was resolved and there was no evidence of erythema at either the lumbar or caudal puncture sites. The patient complained of mild sore throat and diarrhoea. There was no evidence of a cauda equina syndrome or epidural abscess. Blood cultures were taken and the patient was admitted for observation. Over the next $24 \mathrm{hr}$, the fever abated, the diarrhoea settled and symptoms of an upper respiratory tract infection persisted. The patient was then discharged with a diagnosis of upper respiratory tract infection.

Follow-up at four weeks time revealed the patient to be doing very well with no further problems. He has successfully undergone several more intrathecal methotrexate treatments without difficulty.

\section{Discussion}

Subarachnoid-cutaneous fistula following intrathecal injection is rare. However, when it does occur it can result in patient distress, postdural puncture headache and a portal of entry for infective organisms. This patient did not appear to have a headache but was at risk for menningitis due to his immonocompromised state.

Management options include conservative measures, surgical repair and epidural blood patch. ${ }^{3-7,12,13}$ Conservative measures include bedrest, time and symptomatic treatment for an associated headache. Surgical techniques for closure of the subarachnoid-cutaneous fistula expose the patient to the risks associated with general anaesthesia and laminectomy in the prone position. Since the technique of epidural blood patch was described by Gormley in 1960, this method has been very effective in the treatment of adult postdural puncture headaches. ${ }^{8,9}$ The epidural blood patch also carries low risks of complications such as back pain, neck stiffness, headache, radicular nerve pain, 9,10 subdural haematoma and infection. Serious sequelae are rare and the technique is much less invasive than an open surgical procedure.

Treatment of subarachnoid-cutaneous fistula with epidural blood patch has been previously described in the paediatric population. ${ }^{1}$ We describe an alternative approach for performing the epidural blood patch for treatment of subarachnoid-cutaneous fistula. The caudal approach to the epidural space was used because of difficulty in identifying the lumbar epidural space. Identification of the epidural space by the lumbar approach may have been facilitated by the injection of radio-opaque contrast, but it may still have been difficult due to this patient's distorted anatomy and persistent communica- 
tion with the intrathecal space. A \#16-gauge intravenous catheter was used to guide placement of the epidural catheter due to technical difficulties encountered using the Hustead needle by the caudal approach. The use of the intravenous needle and catheter to identify the epidural space by the caudal approach may have certain advantages compared with the use of a sharp or B-bevel (blunt bevel) stainless steel needle alone. Once the loss of resistance was felt, the teflon catheter was slid off the introducer needle $1.5 \mathrm{~cm}$ into the caudal space, thus reducing the risk of venous or dural puncture. The use of the epidural catheter was thought to be necessary in order to place the blood patch as close to the dural rent as possible. In this case, confirmation of the location of the epidural catheter was not made but it was assumed to be in the lumbar region. During the procedure, we discussed the use of fluorscopy if the procedure had failed. Because of the immediate discontinuation of CSF flow with the injection of the blood patch through the epidural catheter, we felt that fluroscopy was unnecessary but would have been of excellent educational benefit. With the use of the multiport epidural catheter the patient's blood was deposited in the epidural space and was successful in preventing further CSF leakage. We believe this is the first time that this method has been used for the placement of an epidural blood patch in a paediatric patient with a continuous CSF leak.

Although the epidural blood patch was successful in managing this subarachnoid-cutaneous fistula, prevention of this complication should be sought. Risks of postdural puncture headaches have decreased dramatically with the use of smaller calibre needles and the introduction of newer needle designs such as the pencilpoint tips which result in less damage to the dura on insertion. The risks of subarachnoid-cutaneous fistulas should, therefore, also be diminished. Alternating the interspace used for repeated intrathecal injections has not been studied in regard to the incidence of postdural puncture headaches or subarachnoid-cutaneous fistulas but intuitively would seem to be beneficial. Although not without its hazards, the authors believe that monitored sedation by anaesthetists may aid in paediatric patient cooperation for invasive procedures such as dural punctures.

\section{References}

1 Kumar V, Maves T, Barcellos W. Epidural blood patch for treatment of subarachnoid fistula in children. Anaesthesia 1991; 46: 117-8.

2 Muñoz H, Rufs J, Dagnino J, Bugedo G, de la Fuente J. Headache following spinal puncture: treatment with epiural blood patch in a 7-year-old patient. Rev Med Chil 1991; 119: 680-2.

3 Gass $H$, Goldstein AS, Ruskin R, Leopold NA. Chronic postmyelogram headache. Isotopic demonstration of dural leak and surgical care. Arch Neurol 1971; 25: 168-70.

4 Brown BA, Jones OW Jr. Prolonged headache following spinal puncture. Response to surgical treatment. J Neurosurg 1962; 19: 349-50.

5 Cullen SC. Current comment. Anesthesiology 1960; 21: 565-6.

6 Crawford JS. Experiences with epidural blood patch. Anaesthesia 1980; 35: 513-5.

7 Rosenberg PH, Heavner JE. In vitro study of the effect of epidural blood patch on leakage through a dural puncture. Anesth Analg 1985; 64: 501-4.

8 Digiovanni $A J$, Galbert $M W$, Wahle WM. Epidural injection of autologous blood for postlumbar-puncture headache. Anesth Analg 1972; 51: 226-32.

9 Ostheimer GW, Palahnuik RJ, Shnider SM. Epidural blood patch for post-lumbar-puncture headache (Letter). Anesthesiology 1974; 41: 307-8.

10 Abouleish E, de la Vega S, Blendinger I, Tio T-O. Longterm follow-up of epidural blood patch. Anesth Analg 1975; 54: 459-63.

11 Edelman $J D$, Wingard $D W$. Subdural hematomas after lumbar dural puncture. Anesthesiology 1980; 52: 166-7.

12 Katz J. Treatment of a subarachnoid-cutaneous fistula with an epidural blood patch. Anesthesiology 1984; 60: 603-4.

13 Longmire S, Joyce TH III. Treatment of a duro-cutaneous fistula secondary to attempted epidural anesthesia with an epidural autologous blood patch. Anesthesiology 1984; 60: 63-4. 